\title{
Differential role of tyrosine phosphorylation in the induction of apoptosis in T cell clones via CD95 or the TCR/CD3- complex
}

\author{
Hans-Heinrich Oberg ${ }^{1}$, Beate Lengl-Janßen ${ }^{1}$, Michael J. \\ Robertson $^{2}$, Dieter Kabelitz ${ }^{1}$ and Ottmar Janssen ${ }^{1,3}$ \\ 1 Department of Immunology, Paul-Ehrlich-Institute, D63225 Langen, Germany \\ 2 Division of Hematology/Oncology, Indiana University Medical Center, \\ Indianapolis, Indiana, USA \\ 3 corresponding author: tel: +49-6103-775000; fax: +49-6103-771253; \\ e-mail: Janssen@em.uni-frankfurt.de
}

Received 4.2.97; revised 10.3.97; accepted 11.3.97

Edited by G. Melino

\begin{abstract}
Activated $T$ cells undergo apoptosis when the Fas-antigen (APO-1, CD95) is ligated by Fas Ligand (FasL) or agonistic anti-Fas antibodies. Repeated stimulation of T lymphocytes via the TCR/CD3-complex induces activation-induced cell death (AICD) associated with FasL surface expression. FasL binding to Fas molecules triggers the Fas-dependent death signaling cascade. Since it is still controversial whether Fasinduced cell death is associated with tyrosine kinase activity, we investigated the tyrosine kinase activation requirements in anti-Fas antibody-induced cell death and AICD in human $T$ cell clones. We report that cell death triggered by anti-Fas antibody is not accompanied by an increase in tyrosine phosphorylation and cannot be blocked by inhibitors of protein tyrosine kinases (PTK). Under the same conditions, AICD of T cell clones is clearly associated with tyrosine kinase activation. In fact, semiquantitative RT-PCR analysis of FasL mRNA expression triggered in T cell clones via the TCR/CD3-complex revealed that tyrosine phosphorylation is required for functional FasL mRNA and surface expression.
\end{abstract}

Keywords: human, $\mathrm{T}$ lymphocytes, apoptosis, signal transduction, tyrosine phosphorylation, CD95, T cell receptor

Abbreviations: AICD, activation-induced cell death; FasL, Fas ligand; PI, Propidium iodide; PTK, protein tyrosine kinase

\section{Introduction}

At least two major cell death pathways exist in activated mature T cells. The first pathway is induced via the interaction of cell surface Fas antigen (CD95, APO-1) with the corresponding Fas ligand (FasL) or ligation of the Fas molecule with agonistic anti-Fas antibodies (see Nagata and Golstein, 1995 for review). The second cell death pathway, also referred to as activation-induced cell death (AICD), can be initiated in preactivated mature $T$ lymphocyte by ligation of the TCR-CD3-complex or other surface structures such as CD2 (Janssen et al, 1991; Wesselborg et al, 1993a,b; Kabelitz et al, 1993). It has been shown recently that the two pathways are causally related and in concert play a critical role in immune selection, target cell destruction and immune response termination (Russel, 1995).

The intracellular mechanisms of Fas-induced or activation-induced cell death are not precisely understood. Cross-linking antibodies to Fas or FasL in its trimeric form induce apoptosis in most Fas-positive cells indicating that close proximity of the cytoplasmic tails of several Fas-molecules is required to activate downstream molecules (Dhein et al, 1992; Suda and Nagata, 1994). The Fas-triggered pathway is independent of extracellular $\mathrm{Ca}^{2+}$ (Rouvier et al, 1993), does not require macromolecular synthesis (Yonehara et al, 1989; Itoh et al, 1991; Klas et al, 1993; Stalder et al, 1994; Golstein et al, 1994) and can proceed in the absence of a nucleus (Schulze-Osthoff et al, 1994a). It has been suggested that Fas-signals are conveyed via the activation of acidic sphingomyelinases resulting in the production of ceramide, a complex lipid which induces rapid apoptosis in different cell types when added to the culture medium (Cifone et al, 1994; Jarvis et al, 1994). Ceramide mediates Fas-induced apoptosis by activating the ras signaling pathway (Gulbins et al, 1995). Using the cytoplasmic tail of Fas in the yeast two-hybrid system, other putative components of the Fas-mediated death pathway have been identified. Two of these, termed FADD and RIP contain death domains which interact with the death domain of Fas (Chinnaiyan et al, 1995; Stanger et al, 1995). Other potential regulators of Fas-mediated apoptosis are the FAP-1 phosphatase which when overexpressed in Jurkat cells inhibits anti-Fas antibodyinitiated cell death (Sato et al, 1995), or the FAST serine/ threonine kinase that is activated upon Fas- but not upon TCR/CD3-ligation in Jurkat cells (Tian et al, 1995).

By co-immunoprecipitation strategies with anti-CD95 $\mathrm{mAb}$, four cell death associated proteins (CAP, for cytotoxicity-dependent APO-1-associated proteins) have been identified which in concert with the intracellular part of CD95 form a death inducing signaling complex (DISC) (Kischkel et al, 1995). Two of these proteins (CAP1, CAP2) were recognized by anti-MORT-1 (anti-FADD) antibodies (Kischkel et al, 1995). CAP4 encodes a novel $55 \mathrm{kDa}$ protein termed FLICE (also MACH) which shares homology to FADD and ICE-like cysteine proteases (Muzio et al, 1996; Boldin et al, 1996). It was also suggested that CAP3 represents the FLICE prodomain which remains bound to Fas upon proteolytic activation (Muzio et al, 1996). 
Eischen and colleagues reported that in Jurkat T cells as well as in $\mathrm{CD}^{+} \mathrm{U} 5^{+} \mathrm{U} 7$ and NK cells, tyrosine kinase activation provides an early and requisite signal for Fasinduced apoptosis (Eischen et al, 1994). However, so far no tyrosine kinase has been shown to directly interact with the cytoplasmic portion of the Fas molecule or to be selectively activated following Fas ligation. In addition, the finding that Fas-induced apoptosis can be blocked very efficiently with protein kinase inhibitors such as Herbimycin A, Genistein and Staurosporine (Eischen et al, 1994) is controversial (SchulzeOsthoff et al, 1994b; Schraven and Peter, 1995; Janssen et al, 1996). In line with the aforementioned report (Eischen et al, 1994), in a previous study with Jurkat cells, we also observed a rapid and transient tyrosine phosphorylation when the Fas molecule was ligated with cross-linking antibodies (IgM isotype) on parental Jurkat cells (Janssen et al, 1996). The pattern of tyrosine phosphorylated proteins resembled the pattern seen upon TCR/CD3-ligation and was similar to the one described by Eischen et al. However, our analysis of various Jurkat-subclones clearly revealed that Jurkat variant cells were efficiently killed by anti-Fas mAb in the absence of detectable tyrosine phosphorylation (Janssen et al, 1996).

Similar results were obtained by other investigators when various Jurkat subclones were analyzed that lacked p56 ${ }^{\text {lck }}$ or CD45 activity (Schraven and Peter, 1995; Oyaizu et al, 1995; Latinis and Koretzky, 1996). These studies clearly demonstrated that neither p56 ${ }^{\text {lck }}$ nor CD45 phosphatase activity are required to mediate Fas-induced cell death. In addition, in the same study, Latinis and Koretzky provided preliminary evidence that Fas-triggering induces serine/threonine kinase activity (Jun kinase) rather than tyrosine phosphorylation. Furthermore, when analyzing the formation and phosphorylation of the death inducing complex formed around the cytoplasmic tail of CD95, Kischkel and colleagues failed to detect tyrosine phosphorylation but found serine phosphorylation of associated CAPs (Kischkel et al, 1995).

A

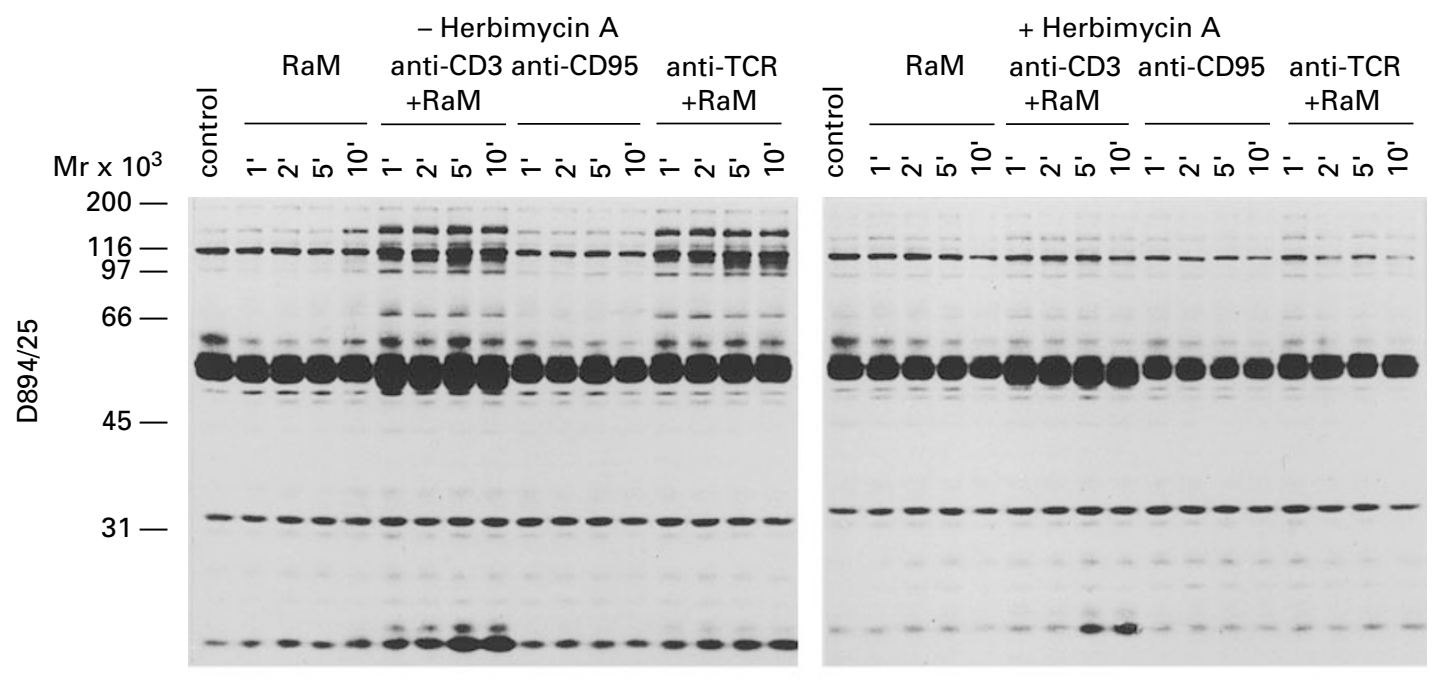

B
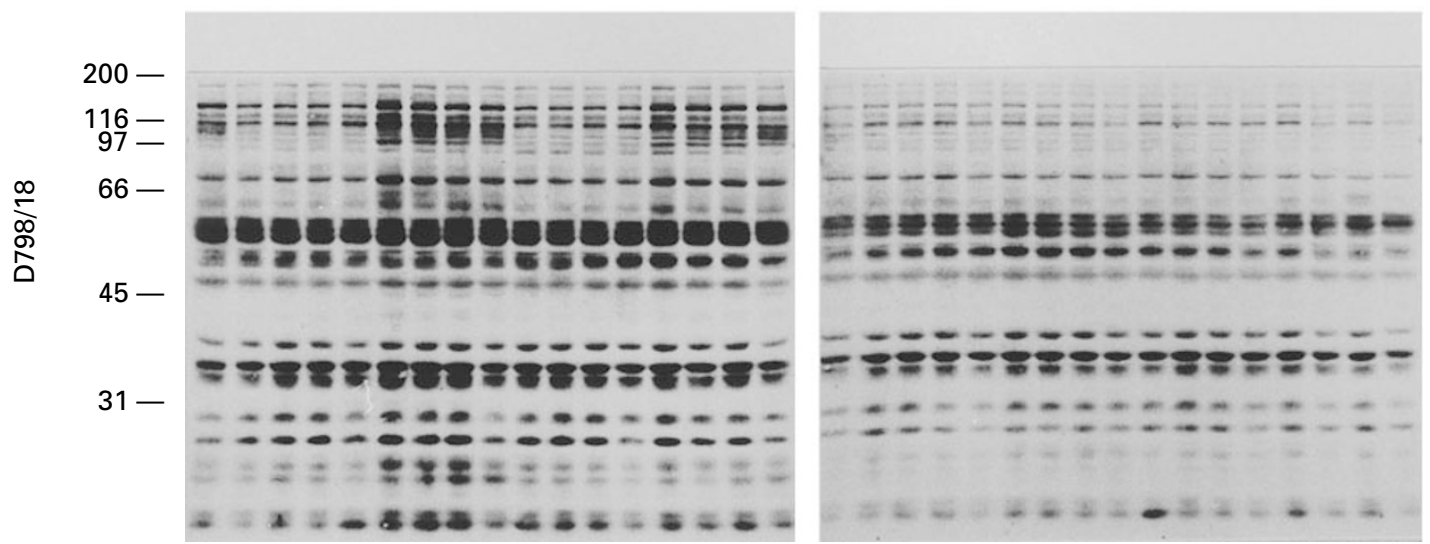

Figure 1 Tyrosine phosphorylation in whole cell lysates following short-term TCR/CD3- or CD95-stimulation. Clone cells (clones D894/25 (A) and D798/18 (B)) were kept in medium or preincubated with Herbimycin A for three hours prior to stimulation. $1.5 \times 10^{6}$ cells per sample were then incubated for 1 to 10 min with the anti-CD3, anti-CD95 or anti-TCR antibodies. Rabbit anti-mouse (RaM) antibodies used to cross-link IgG isotype antibodies against the TCR or CD3 served as a control. Following incubation in a prewarmed antibody solution $\left(37^{\circ} \mathrm{C}\right)$, the cells were washed once in cold PBS and immediately lysed in NP40 lysis buffer. Proteins separated by SDS-PAGE were transferred to Nitrocellulose membranes and phosphotyrosine-containing proteins were detected with mAb 4G10, horseradish- 
To further characterize the role of tyrosine kinase activation in cell death of IL-2-dependent, non-transformed human $\mathrm{T}$ lymphocytes, we compared the tyrosine phosphorylation requirements in TCR/CD3-mediated AICD and anti-Fas antibody-induced apoptosis in different $\mathrm{T}$ cell clones. Our data clearly demonstrate that Fas-mediated cell death is independent of detectable short-term tyrosine phosphorylation. In addition, in all $\mathrm{T}$ cell clones tested, CD95-induced cell death could not be blocked by inhibitors of PTKs such as Herbimycin A. By contrast, TCR/CD3mediated AICD was almost completely abrogated when AICD-sensitive clone cells were pretreated with the inhibitor of src-related kinases. As analyzed by a semiquatitative RT-PCR approach, we also demonstrate that Herbimycin A blocks AICD at the level of FasL mRNA expression. The data presented here fit into the concept that tyrosine kinase activity plays a pivotal role in TCR/ CD3-triggered AICD being neccessary for the induction of FasL expression. The induction of CD95-mediated death, however, is independent of PTK activity and likely to be regulated 'more directly', e.g. due to the intrinsic protease activity of Fas-associated FLICE/MACH (Muzio et al, 1996; Boldin et al, 1996).

\section{Results \\ CD95-ligation does not induce tyrosine phosphorylation in human $\mathbf{T}$ cell clones}

Since there is a still on-going discussion whether or not CD95-induced cell death is associated with rapid changes in the tyrosine phosphorylation in some cell types and not in others (Eischen et al, 1994; Schulze-Osthoff et al, 1994b; Schraven and Peter, 1995; Janssen et al, 1996), we analyzed the phosphoprotein patterns within whole cell lysates of non-transformed human $\mathrm{T}$ cell clones stimulated with $\mathrm{mAb}$ against the TCR/CD3-complex or CD95, respectively. All tested clones expressed comparable levels of TCR/CD3 and CD95 antigen (not shown). As demonstrated in Figure 1 for two representative clones (D894/25 (A), D798/18 (B)), CD3- or TCR-ligation induced the rapid phosphorylation of a characteristic and similar set of proteins as detected by a sensitive Western blotting technique using enhanced chemiluminescence. In agreement with our previous report on tyrosine phosphorylationindependent CD95-induced apoptosis in leukemic human $\mathrm{T}$ cell lines (Janssen et al, 1996), we did not detect a significant increase in tyrosine phosphorylation upon stimulation (here shown up to $10 \mathrm{~min}$ ) with anti-CD95 antibodies or rabbit anti-mouse cross-linking antibodies used as a control for TCR/CD3-stimulation (Figure 1). We also failed to detect changes in tyrosine phosphorylation upon longer exposure (up to $2 \mathrm{~h}$ ) of clone cells to anti-CD95 mAb (data not shown).

\section{Inhibition of AICD but not Fas-induced cell death by Herbimycin $A$}

Next, we analyzed whether TCR/CD3- and/or CD95induced death of $\mathrm{T}$ cell clones depended on protein tyrosine kinase activity and thus could be influenced by PTK-inhibitors. As also shown in Figure 1, TCR/CD3induced tyrosine phosphorylation was efficiently reduced by pretreatment with the tyrosine kinase inhibitor Herbimycin A. We therefore determined the fraction of clone cells that underwent apoptosis during overnight incubation in medium alone or with anti-CD3-, anti-CD95- or anti-TCR mAb in the presence or absence of PTK inhibitors. We used two different methods to analyze cell death, i.e. Pl-staining of dead cells and determination of absolute numbers of viable cells by standard cell dilution assay (SCDA). Representative experiments for clones D894/25 (A), and D798/18 (B), are shown in Figure 2 (PI-staining) and for all tested clones in Figure 3 (SCDA), respectively. As judged by PI-staining, in individual experiments, the fraction of dead cells following overnight incubation in the presence of $2 \mu \mathrm{g} / \mathrm{ml}$ anti-Fas antibody 7C11 was between 43 and $91 \%$ (mean $74 \pm 17 \%$ ). All five clones underwent AICD when stimulated with anti-CD3 or anti-TCR mAb (24 to $91 \%$ apoptopic cells (mean $65 \pm 23 \%)$ ). In the experiments shown in Figure 2, incubation of clones D894/25 (A) or D798/18 (B) with soluble anti-CD3 or anti-TCR $m A b$ resulted in a significant increase in the number of apoptotic cells. The fraction of dying cells was calculated based on fluorometric analyses following $\mathrm{Pl}$-staining with small PI-negative cells with reduced forward and side scatter properties considered to be in the process of undergoing apoptosis. Thus, when compared to $10 \%$ apoptotic cells in the absence of antibodies, $31 \%$ (A) or $24 \%$ (B) of the cells underwent apoptosis upon CD3-stimulation and $67 \%$ or $61 \%$ upon
$\mathrm{D} 894 / 25$

Herbimycin A + Herbimycin A
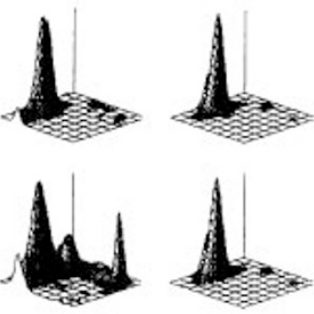

anti-CD95
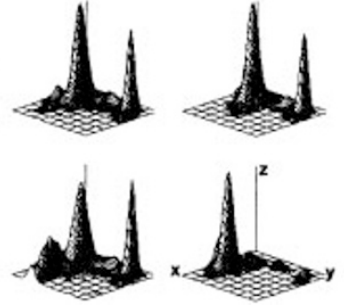

- Herbimycin A + Herbimycin A
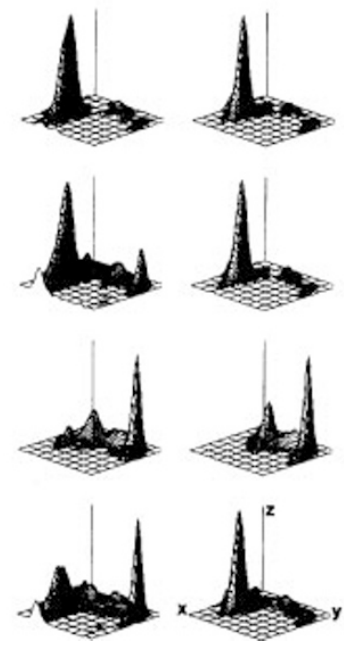

Figure 2 Pl-staining of dead clone cells. $10^{6}$ cells (clone D894/25 (A) and D798/18 (B)) were incubated overnight in $1 \mathrm{ml}$ of culture medium in the presence or absence of soluble anti-CD3, anti-CD95 or antiTCR antibodies with or without Herbimycin A. Dead cells were stained with Propidium iodide. The cell size (forward scatter=FSC, $x$ axis) is plotted against the relative cell number ( $z$-axis) and the red fluorescence intensity (FL-2, y-axis). 

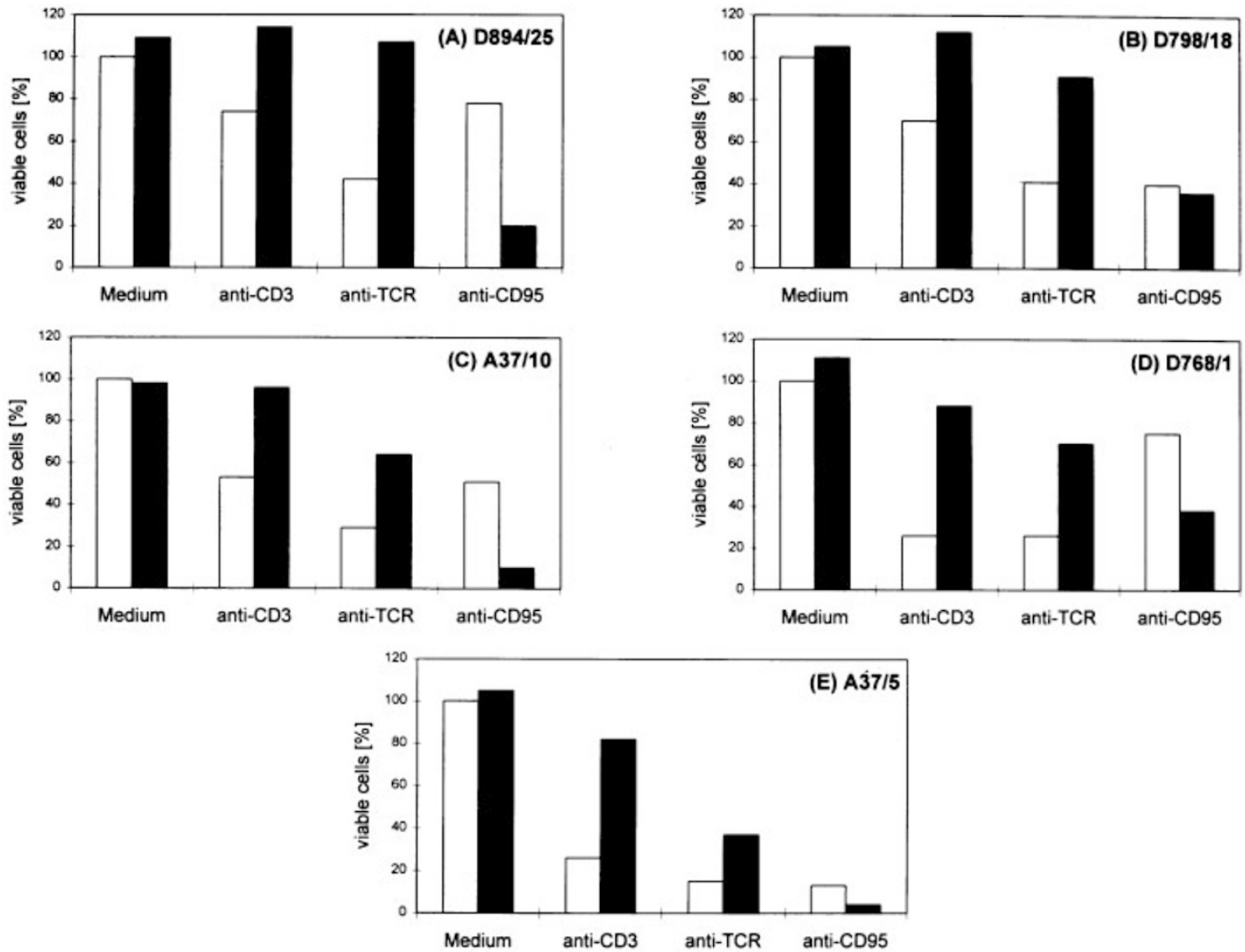

Figure 3 Inhibition of AICD but not Fas-induced apoptosis by Herbimycin A. Cell viability of clone cells was analyzed using the SCDA protocol. The cells were incubated in IL-2-containing medium alone or with anti-CD3, anti TCR or anti-CD95 mAb in the absence (white bars) or presence (black bars) of Herbimycin A. Five different T cell clones were tested (A-E). Values are given as per cent viable cells normalized to the medium control in the absence of Herbimycin A (set to $100 \%$ ).

TCR-stimulation. All clones were susceptible to $7 \mathrm{C} 11-$ mediated cell death. The fraction of dead or apoptotic cells upon incubation in the presence of anti-CD95 mAb was 43, 80 or $87 \%$, respectively (Figure 2 ). Although slight changes in the cell size were noted, treatment of D894/25 or D798/ 18 clone cells with $1.5 \mu \mathrm{M}$ Herbimycin $\mathrm{A}$ did not significantly affect the viability in medium alone (e.g., $15 \%$ and $12 \%$ apoptotic cells, respectively, in the experiment shown in Figure 2). However, in these clones, Herbimycin A very efficiently blocked AICD in the presence of anti-CD3 or anti-TCR mAb - but enhanced anti-Fas antibody induced cell death.

Similar results were obtained when cell viability instead of cell death was analyzed in a standard cell dilution assay (SCDA, Figure 3). The data shown in Figure 3 were normalized to the medium control in the absence of Herbimycin A (set to $100 \%$ ). Cell viability in TCR/CD3stimulated cultures was significantly restored in all five $T$ cell clones in the presence of Herbimycin A (Figure $3 \mathrm{~A}-$ E). By contrast, anti-CD95-induced cell death was unaffected or even enhanced in the presence of PTK inhibitor. Herbimycin A alone did not protect any of the clones from CD95-induced cell death but rather significantly increased the number of dead cells in four of the five tested clones exposed to anti-CD95 mAb.

\section{Herbimycin A inhibits TCR/CD3- but not CD95-driven DNA-fragmentation}

We also analyzed the DNA-degradation in methanol-fixed cells following overnight incubation with or without Herbimycin $A$ in the presence or absence of anti-TCR, anti-CD3 or antiCD95 mAb (Figure 4). Cell death as analyzed in Figure 2 was accompanied by the appearence of hypodiploid DNAfragments indicative of endonuclease activity. Shown for clones D894/25 (A) and D798/18 (B) in Figure 4, anti-CD3 or anti-TCR-induced DNA-degradation was markedly reduced in the presence of Herbimycin A. By contrast, CD95-induced DNA fragmentation was not affected or even enhanced. The results of other experiments using the different $T$ cell clones strictly correlated with the data presented for PI-staining and SCDA.

\section{Effects of other kinase inhibitors on AICD or Fas-induced apoptosis}

The effects of other inhibitors of signaling proteins such as Staurosporine (Tamaoki et al, 1986), Genistein (Akiyama et al, 1987), Tyrphostin (Gazit et al, 1989), and Wortmannin (Powis et al, 1994) on AICD or CD95-induced apoptosis were analyzed primarily with regard to the inhibition of cell death in 
A

D894/25
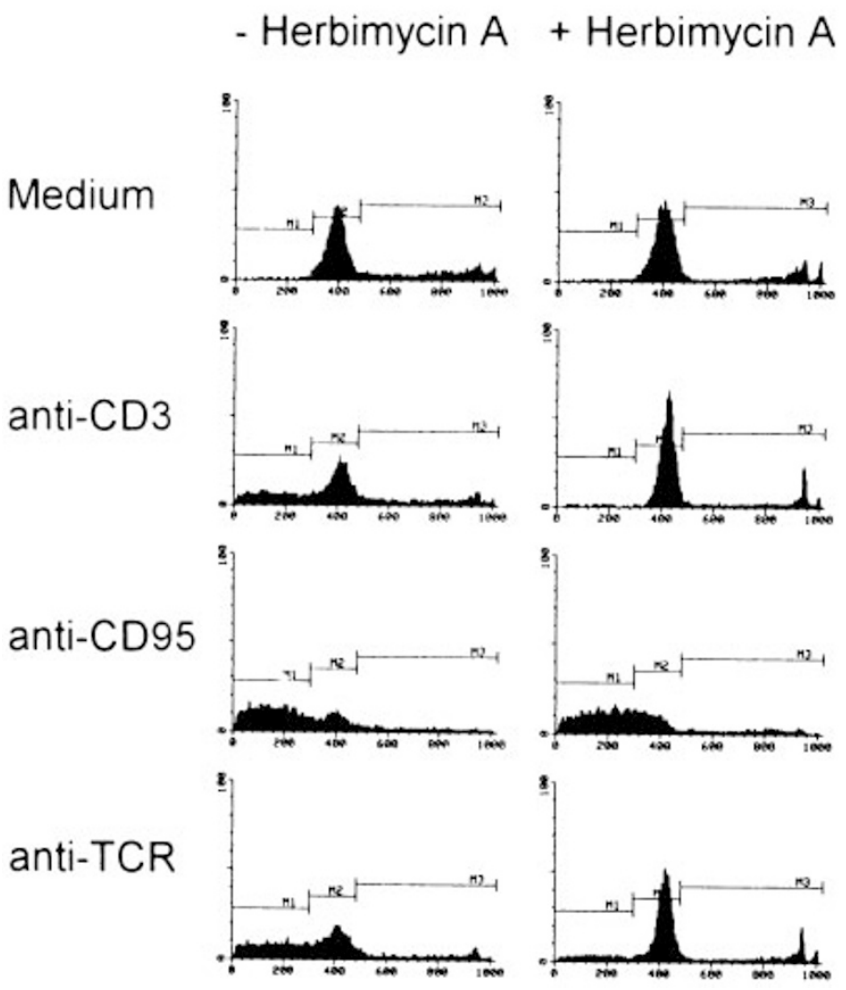

B

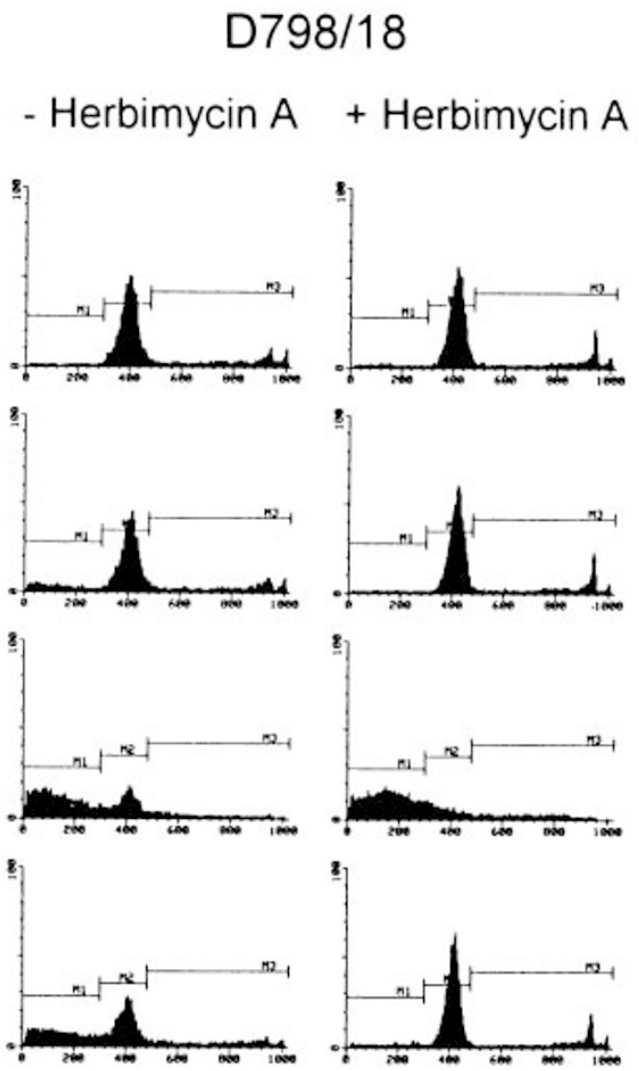

Figure 4 Inhibition of TCR/CD3-induced but not CD95-induced DNA fragmentation by Herbimycin A. Clone cells (clones D894/25 (A) and D798/18 (B)) were stimulated overnight in the presence or absence of Herbimycin A with medium alone or soluble anti-CD3, anti-CD95 or anti-TCR antibodies, respectively. Cells were either kept in medium alone or in the presence of Herbimycin A for three hours prior to stimulation. The DNA content was analyzed following fixation with methanol and DNA-staining with Propidium iodide. Red fluorescence intensity (FL-2, x-axis) is plotted against the relative number of events aquired.

overnight cultures of clone cells stimulated with anti-TCR/ CD3 reagents or anti CD95 antibodies, respectively. It should be noted that higher doses of all tested inhibitors (especially of Staurosporine) resulted in the induction of cell death in a significant fraction of clone cells by themselves. The 'nontoxic' concentrations that we used for inhibition experiments usually were $1: 2$ or $1: 5$ dilutions of doses that induced low level but significant apoptosis in the absence of any other stimulus. In such experiments, all four inhibitors sometimes showed a minor inhibitory effect on AICD (maximum inhibition $10-20 \%$ ). However, in our hands, Herbimycin A was the only inhibitor that reproducibly and significantly blocked activationinduced cell death as demonstrated in the experiment with clone D894/25 shown in Figure 5. As can be seen, Herbimycin A not only blocked AICD triggered by anti-CD3 or anti-TCR $m A b$, but also AICD triggered by more physiological TCRdependent stimuli such as superantigen SEA (Kabelitz and Wesselborg 1992). Of note, in most experiments, Genistein also accelerated but never inhibited CD95-induced death.

\section{Herbimycin A blocks FasL mRNA and surface expression}

It has been shown that in different T cell populations, TCRmediated cell death is associated with the tyrosine kinase-

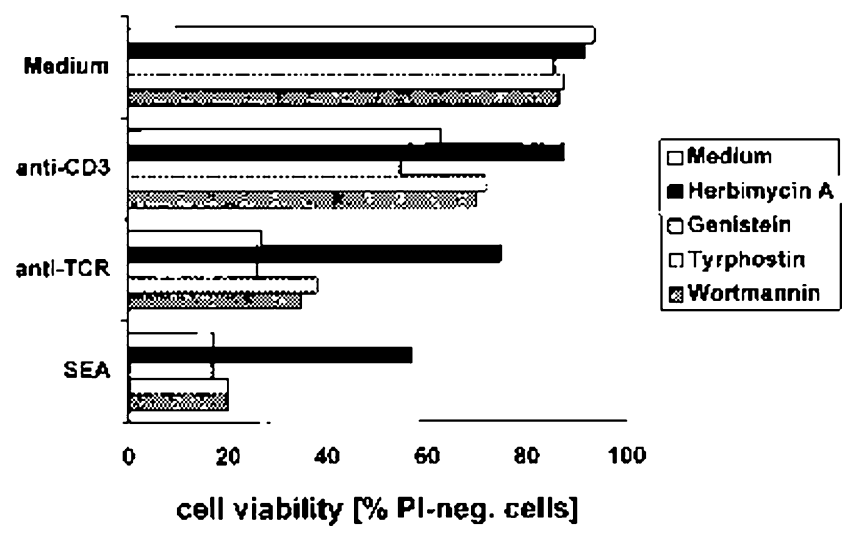

Figure 5 Effects of kinase inhibitors on AICD. Clone cells (clones D894/25) were stimulated overnight in the presence or absence of PTK-inhibitors at concentrations indicated in the Materials and Methods section and with medium alone or soluble anti-CD3 or anti-TCR antibodies, or Staphylococcal enterotoxin A. Cell viability was analyzed by staining with Propidium iodide.

dependent activation of FasL expression (Oyaizu et al, 1995; Migita et al, 1994; Orchansky and Teh, 1994; Vignaux et al, 1995; Anel et al, 1994). To test whether the inhibitory effect of Herbimycin A can be explained by differences in the 
A

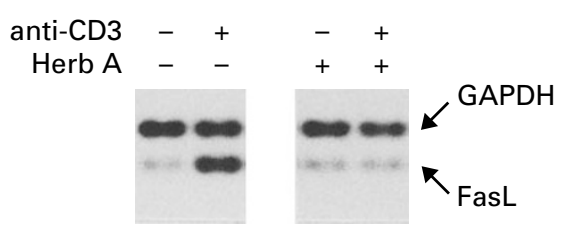

B
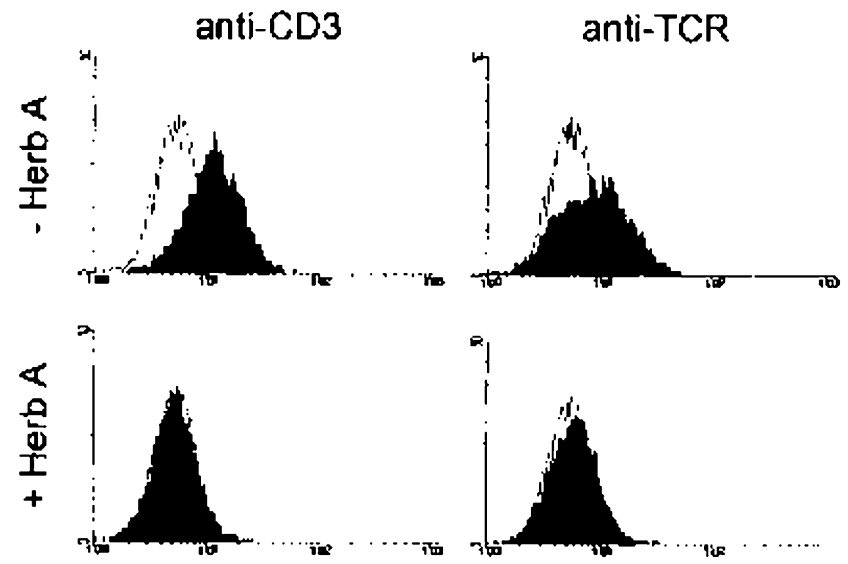

Figure 6 TCR/CD3-induced FasL mRNA (A) and FasL surface expression (B) in AICD is blocked by PTK inhibitor pretreatment. (A) RT - PCR-analysis of FasL mRNA expression in D894/25 cells with or without pretreatment with Herbimycin $A$ and with or without stimulation with anti-CD3 mAb. The clone cells were pretreated for $3 \mathrm{~h}$ in Herbimycin $A$ and thereafter incubated for $3 \mathrm{~h}$ with or without anti-CD3 (OKT3). The cells were then harvested and total RNA was subjected to RT-PCR. GAPDH served as a control for equal amounts of RNA prior to the PCR. (B) FACS-analysis of FasL expression on D894/25 cells with or without stimulation with anti-CD3 and anti-TCR mAb, respectively. The cells were pretreated for $3 \mathrm{~h}$ with Herbimycin $\mathrm{A}$, then incubated for $3 \mathrm{~h}$ with or without anti-TCR/CD3 mAb, and analyzed using a biotinylated anti-FasL mAb and Streptavidin-PE.

inducibility of FasL mRNA or protein expression in T cell clones, we analyzed FasL mRNA induction in clones following stimulation with anti-TCR/CD3 mAb. As shown in Figure 6A, RT - PCR analyses of FasL mRNA from unstimulated or CD3stimulated D894/25 cells pretreated with Herbimycin A revealed that in fact the PTK-inhibitor significantly prevented the CD3-stimulated induction of FasL mRNA expression. We also analyzed FasL surface expression using a biotinylated anti-FasL mAb with Streptavidin-PE (Figure 6B). Again, we compared the expression of FasL surface molecules on clone cells pretreated with the PTK-inhibitor and incubated in medium alone or in the presence of anti-CD3 mAb. As expected from the RT-PCR analysis of D894/25 cells, we detected a lack of the induction of cell surface FasL expression on clone cells that had been pretreated with Herbimycin A.

\section{Discussion}

We have analyzed the role of tyrosine phosphorylation in Fasand TCR/CD3 induced cell death in several non-transformed, IL-2-dependent human T cell clones. Using the agonistic antihuman CD95 mAb 7C11 (IgM), we clearly demonstrate that at a clonal level, anti-Fas antibody-triggered cell death is not dependent on early tyrosine phosphorylation. By contrast,
AICD triggered via ligation of the TCR/CD3-complex is associated with and dependent on rapid activation of tyrosine, probably src-related, kinases. Therefore, AICD can be efficiently reduced by Herbimycin $A$, a potent inhibitor of src-type protein tyrosine kinases (June et al, 1990; Uehara et al, 1989) which blocks tyrosine phosphorylation-dependent FasL mRNA (and surface) expression. The data presented here extend our previous results with transformed leukemic Jurkat cells (Janssen et al, 1996) to the analysis of nontransformed normal $\mathrm{T}$ cells at the clonal level.

However, our results contradict the study of Eischen et al, reporting that in Jurkat $\mathrm{T}$ cells, tyrosine kinase activation provides an early and requisite signal for Fas-induced cell death (Eischen et al, 1994) and also a more recent study by Mollereau et al, describing tyrosine-phosphorylationdependent CD2-induced apoptosis and also (less prominent) tyrosine phosphorylation upon Fas ligation in activated human T cells (Mollerau et al, 1996). It should be stressed that in our previous study (Janssen et al, 1996), we also reported that CD95-ligation induced tyrosine phosphorylation in parental Jurkat cells. In our experiments, we used similar concentrations of anti-CD95 antibodies (although we used different clones) and similar stimulation and lysis conditions as reported by Eischen and colleagues. These 'normal' Jurkat cells expressed Fas molecules and high levels of TCR and especially CD3 molecules. However, when testing a set of CD3-negative Jurkat subclones that undergo CD95-induced cell death, we had to conclude that CD95-induced cell death occured independent of PTK activation and that the observed phosphorylation in parental Jurkat cells was likely to be a result of co-cross-linking of PTK-associated molecules such as the TCR/CD3-complex (Janssen et al, 1996).

Our results are in full agreement with those reported by Schraven and Peter (1995), Oyaizu and colleagues (1995), and Latinis and Koretzky (1996) for p56 lck - or CD45negative Jurkat variants, respectively. In their studies, PTKinhibitors also failed to block CD95-induced apoptosis. Oyaizu et al, reported that in their hands, TCR/CD3induced cell death is abrogated in $\mathrm{p} 56^{\text {lck }}$-deficient $\mathrm{JCaM}$ cells when compared to parental JE6.1 cells. Taken together, from these studies one has to conclude that at least src-type kinases are not involved in CD95-mediated apoptosis as had been suggested by Eischen et al. By contrast, although the significance has to be proven, Latinis and Koretzky, (1996) suggested a Fas-mediated JNK (Jun Kinase, a serine-threonine kinase) activation with a clearly different time course kinetics as compared to the fast tyrosine phosphorylation reported by Eischen and colleagues.

On the other hand, it should also be mentioned that a recent report by Atkinson et al (1996) suggested a physical interaction between Fas and $\mathrm{p} 59^{\mathrm{fynT}}$ and a role of fyn in the regulation of Fas-mediated death and killing in murine $T$ cells. From their observations in fyn knockout mice, it was concluded that fyn plays an important role in Fas signal transduction. However, one could also envision that in fyn knockout mice, activation-induced expression of the FasL is reduced which could also explain the elevated lifespan of activated $T$ cells. Further, it has been suggested that fyn 
plays an important role in the stabilization of FasL expression due to an interaction of the intracellular part of FasL with SH3 domains of the kinase (Hane, 1995). Our data showing that CD95-ligation does not directly increase tyrosine phosphorylation and that a specific inhibitor of src kinases does not block anti-CD95-induced apoptosis in untransformed human $\mathrm{T}$ cell clones, do not exclude that fyn and/or Ick do have some impact on e.g. the lifespan via a potentially tyrosine phosphorylation-independent adaptor function through $\mathrm{SH} 2$ or $\mathrm{SH} 3$ domains.

Tyrosine phosphorylation plays a crucial role in TCR/ CD3- (and CD2-) triggered AICD. It is well established that TCR/CD3-engagement induces tyrosine kinase-dependent signaling cascades which may or may not be accompanied by an increase in tyrosine phosphorylation of downstream second messenger molecules (Wange and Samelson, 1996; Rudd, 1994). However, it is still unclear which intracellular signaling molecules form switch points for the different outcomes (proliferation, cytokine production, AICD) following receptor activation. It is also not known how these molecules are activated or silenced in favour of the apoptosis pathway in stimulated cells. Thus, it has been reported for thymocytes that protein tyrosine kinase inhibitors such as Herbimycin A or Genistein prevent antiCD3- but not glucocorticoid-induced apoptosis (Migita, 1994). Further, in proliferating murine T cells, AICD has been shown to be associated with altered phosphorylation of the various CD3 subunits (Orchansky, 1994) and in murine $T$ cell hybridomas, signaling events most probably involving tyrosine kinase-dependent phosphorylation of tyrosine based motifs within the CD3 $\zeta$-chains lead to rapid expression of FasL (Vignaux 1995). Importantly, in mouse cytotoxic $T$ cell clones, the TCR-induced FasL expression could be blocked by PTK inhibitors Genistein and Herbimycin A (Anel, 1994).

Whether TCR/CD3-triggered AICD in previously stimulated $T$ cells is mediated exclusively by Fas/FasL interactions or can at least in part also proceed when the Fas/FasL interaction is not operational is still not known. Several reports addressing the role of Fas/FasL in AICD indicate that blocking the Fas/FasL interaction during AICD (e.g. by Fas-Ig fusion proteins or anti-Fas antibody fragments) results in a substantial reduction of cell death (Alderson et al, 1995; Dhein et al, 1995; Brunner et al, 1995; Ju et al, 1995). These data in conjunction with many data on TCR/CD3-induced tyrosine phosphorylation suggest that the initial activation of protein tyrosine kinases as a consequence of surface receptor ligation (Wange and Samelson, 1996) may in fact be required as a crucial and indispensable step in TCR/CD3triggered, Fas-dependent apoptosis. Our data presented here demonstrate that AICD as well as TCR/CD3-induced DNA-fragmentation can be efficiently blocked in AICDsusceptible human $T$ cell clones by inhibition of src-type PTKs with Herbimycin A. Our analysis of FasL mRNA and surface expression clearly shows that this PTK-inhibitor blocks the level of FasL expression at an early stage before mRNA transcription and that on a clonal level this inhibition is sufficient to almost completely block AICD. The fact that Herbimycin $A$, which is a specific inhibitor of src-related kinases was the only inhibitor in our hands to reproducibly reduce $A I C D$ in all experiments, points to an essential role of the src-type kinases p56 $6^{\text {lck }}$ or p59 fyn in TCR/CD3-AICD. This is compatible with data from p56 $6^{\text {lck }}$ deficient leukemic cells (Oyaizu et al, 1995; Latinis and Koretzky, 1996). Of note, all inhibitors that we have tested induced apoptosis in IL-2-dependent T cells when used in higher concentrations. The partial (Genistein) or complete uneffectiveness (Staurosporine, Tyrphostin, Wortmannin) of other inhibitors to reduce AICD in human T cell clones further indicates that src-type PTK activity forms an initial step in AICD. Activation of src-related kinases is one of the earliest events in $\mathrm{T}$ cell activation. It results in the initiation of a variety of different signaling cascades including the recruitment and activation of ZAP-70 or PI 3-Kinase, and recruitment of multiple enzymes or adapter proteins to the activation complex (Wange and Samelson, 1996; Rudd et al, 1994). The blocking effect of the srctype kinase inhibitor Herbimycin A on AICD is thus compatible with the essential role of src-related kinases in TCR/CD3 signaling.

The Fas molecule itself most likely utilizes a tyrosine kinase-independent signaling machinery when triggered by agonistic anti-Fas $\mathrm{mAb}$ and presumably by the natural ligand on FasL expressing cells. Various groups have reported that CD95 ligation like engagement of the receptor for TNF- $\alpha$ (Kim et al, 1991; Schütze et al, 1992; Dressler et al, 1992) activates acidic sphingomyelinases which hydrolyze sphingomyelin and result in the production of ceramide (see Gill et al, 1994 for review). It is still an open question which of the potential downstream enzymes of ceramide such as mitogen-activated protein kinase (Raines et al, 1993) or the protein phosphatase 2A (Dobrowsky et al, 1993) become activated following CD95-ligation in T cells. It is also not known whether the expression or activity of the Fas-associated Phosphatase FAP-1 (Sato et al, 1995) is regulated by ceramide. However, it has been reported by Gulbins and colleagues that Fas-induced apoptosis is mediated via a ceramide-initiated activation of the Ras signaling pathway (Gulbins et al, 1995).

Although several components of the death inducing signaling complex (DISC) formed around the Fas molecule have been characterized as key messengers for Fasmediated cell death (Kischkel et al, 1995; Boldin et al, 1996; Muzio et al, 1996), in agreement with the results reported here, there is no evidence for a direct association with PTKs. Thus, we and others failed to detect Fasdependent tyrosine phosphorylation in Fas-susceptible T cell lines and clones (Janssen et al, 1996; Schraven and Peter, 1995). Further, the inhibitory effect of protein tyrosine kinase inhibitors such as Herbimycin A on Fasmediated apoptosis is controversial. Although Eischen et al (1994) have shown an inhibitory effect in several cell lines including Jurkat leukemia cells, Schulze-Osthoff et al (1994a) did not observe a significant inhibition in their analysis of L929 cells. Our data clearly demonstrate that PTK inhibitors do not reduce cell death or DNA-damage upon Fas-stimulation of cloned human T cells. By contrast, in most clones anti-CD95-induced cell death was significantly and reproducibly enhanced when cells had 
been pretreated with Herbimycin A (and in some cases with Genistein) prior to CD95 ligation. This could indicate that tyrosine phosphorylation events are also important in preventing Fas-mediated apoptosis to some extend. In this scenario, it has been reported that the oncogenic PTK Abl can block Fas-induced death (McGahon et al 1995).

It should be emphasized, however, that other groups have reported that serine-threonine rather than tyrosine phosphorylation may play a role in Fas-signaling. Thus, Tian et al (1995) have demonstrated that a serine/threonine kinase (FAST, for Fas-activated serine/threonine kinase) is rapidly dephosphorylated upon CD95-ligation to phosphorylate TIA1, a nuclear RNA-binding protein that has been implicated as an effector of apoptosis (Tian et al, 1991). TIA-1 and the related RNA-binding protein have been implicated in Fasmediated apoptosis (Tian et al, 1995; Taupin et al, 1995). However, the serine/threonine phosphatase which catalyzes dephosphorylation of FAST to activate the kinases is still unknown although it is possible that ceramide-activated phosphatases link Fas-signaling to FAST activation. In addition, a link between ceramide and serine/threonine but not protein tyrosine kinases has been recently suggested by Latinis and Koretzky (1996), demonstrating that the serine/ threonine kinase JNK plays a role in CD95-mediated cell death. Interestingly, JNK-activity is increased with similar kinetics in Jurkat cells following Fas-ligation or C2-ceramidestimulation (also in the absence of p56 $^{\text {lck }}$ or CD45, respectively).

In conclusion, our results clearly demonstrate that in untransformed clonal $\mathrm{T}$ cell populations, Fas-mediated apoptosis does not require rapid tyrosine kinase activation and certainly not the activation of src-related kinases. By contrast, TCR-CD3-induced cell death is dependent on tyrosine kinase-regulated signaling pathways and therefore can be efficiently abolished by blocking PTK-activity with the inhibitor Herbimycin A. The data presented here also substantiate the suggested important role of src-type PTKs in mediating initial signaling events in Fas/FasL-regulated AICD.

\section{Materials and Methods}

\section{$\mathrm{T}$ cell clones}

IL-2-dependent T cell clones were established from normal donors as described (Wesselborg et al, 1991) and grown in RPMl 1640 with $10 \%(\mathrm{v} / \mathrm{v})$ FCS (Biochrom, Berlin, Germany), antibiotics (penicillin at $100 \mathrm{U} / \mathrm{ml}$ and streptomycin at $100 \mu \mathrm{g} / \mathrm{ml})$, L-Glutamine $(2 \mathrm{mM})$ and HEPES buffer solution $(10 \mathrm{mM})$ at $37^{\circ} \mathrm{C}$ in a humidified atmosphere with $6 \% \mathrm{CO}_{2}$. Clones were restimulated periodically with irradiated $\mathrm{PBMC}$ and EBV-transformed lymphoblastoid cell lines in the presence of PHA $(0.5 \mu \mathrm{g} / \mathrm{ml}$, Wellcome, Burgwedel, Germany). Three days after restimulation, dead cells were removed by centrifugation on FicollHypaque density gradients. The clone cells were washed and expanded in the presence of recombinant human rlL-2 $(15 \mathrm{U} / \mathrm{ml}$, EuroCetus, Frankfurt, Germany) for several days before use in the assays. All clones expressed comparable levels of surface CD95, TCR $(\alpha \beta)$ and CD3 molecules. Four of the clones expressed CD4, clone D768/1 was $\mathrm{CD}^{-} \mathrm{CD}^{-}$.

\section{Antibodies and reagents}

For surface staining of CD95, we used anti-human Fas mAb 7C11 (IgM) and $\mathrm{CH} 11$ (IgM, Kamiya Biomedical Company, Thousand Oaks, CA) with FITC-conjugated goat anti-mouse IgG and IgM second step reagents (Tago Inc., Burlingame, CA). MAb $7 \mathrm{C} 11$ was also used for the in vitro induction of cell death and for short-term stimulation. For the induction of AICD and short-term stimulation prior to antiphosphotyrosine immunoblotting, we used anti-CD3 mAb OKT3 (kindly provided by Cilag $\mathrm{GmbH}$, Sulzbach, Germany), and antiTCR $\alpha \beta$ mAb BMA031, (kindly provided by Dr. R. Kurrle, Behringwerke AG, Marburg, Germany), respectively, cross-linked with rabbit antimouse IgG secondary antibodies (Jackson ImmunoResearch Laboratories, West Grove, PA). In some experiments, clone cells were stimulated with Staphylococcus aureus enterotoxin A (SEA, Serva, Heidelberg, Germany) at $1 \mathrm{ng} / \mathrm{ml}$ (Kabelitz and Wesselborg, 1992). Other antibodies used for the characterization of surface molecules included Leu2a (anti-CD8), Leu3a (anti-CD4), Leu4 (antiCD3), Leu5b (anti-CD2), anti-TCR $\alpha \beta$ as FITC- or PE-conjugates (Becton Dickinson, Mountain View, CA) or OKT4 and OKT8, purified from hybridoma supernatants (American Type Culture Collection, Rockville, MD). For the detection of FasL surface expression, we used a Biotin-conjugated mAb (clone NOK-1, Pharmingen, San Diego, CA) together with Streptavidin-PE from Becton Dickinson. Briefly, clone cells (pretreated or not treated with PTK inhibitors) were incubated at $5 \times 10^{5} \mathrm{cells} / \mathrm{ml}$ in the presence or absence of mAb against the TCR/ CD3-complex (2 $\mu \mathrm{g} / \mathrm{ml})$. After $3 \mathrm{~h}$, the cells were washed and stained with the anti-FasL mAb. Cells kept in medium alone served as a control. All fluorometric analyses were performed on an FACScan analyzer (Becton Dickinson) using Lysis II software.

\section{Analysis of cell death, cell viability and DNA fragmentation}

The relative number of dead cells was determined after overnight (18 to 24 hours) incubation in the presence or absence of the indicated agents by staining with the DNA dye Propidium iodide (PI, Sigma, $2 \mu \mathrm{g} /$ $\mathrm{ml}$ in PBS). The absolute number of viable cells in a given population was analyzed in a standard cell dilution assay (SCDA) established in our laboratory (Pechhold et al, 1994). To this end, T cells were labeled with $\mathrm{PE}$-conjugated anti-CD3 $\mathrm{mAb}$ and resuspended in staining buffer containing PI at $0.2 \mu \mathrm{g} / \mathrm{ml}$ and a known number of fixed FITC-labeled standard cells. The absolute number of viable T cells was calculated as the ratio of the relative proportions of $\mathrm{PE}^{+} \mathrm{PI}^{-}$clone cells and $\mathrm{FITC}^{+} \mathrm{PI}^{+}$ standard cells. DNA fragmentation was assayed after overnight incubation of clone cells in 24 well culture plates $\left(10^{6}\right.$ cells $\left./ \mathrm{ml}\right)$ in the presence of anti-CD95 or anti-TCR/CD3 mAb at $2 \mu \mathrm{g} / \mathrm{ml}$. $400 \mu \mathrm{l}$ of icecold methanol were added to $200 \mu \mathrm{l}\left(2 \times 10^{5}\right)$ of resuspended cells and incubated on ice for at least $1 \mathrm{~h}$. The cells were then pelleted and $100 \mu \mathrm{l}$ of DNase-free RNase $(200 \mathrm{U} / \mathrm{ml})$ and $100 \mu \mathrm{l}$ of Pl-buffer containing $100 \mu \mathrm{g} / \mathrm{ml} \mathrm{PI}, 0.1 \%$ (v/v) Triton X-100 and $100 \mu \mathrm{M}$ EDTA were added (Krishan, 1975). After 30 min incubation in the dark, the DNA content was analyzed on a FACScan analyzer.

\section{Anti-phosphotyrosine immunoblotting}

Cells were washed twice in RPMI 1640 with $2 \%$ FCS kept at $37^{\circ} \mathrm{C}$. $1.5 \times 10^{6}$ cells were stimulated per sample. To this end, the cells were pelleted and incubated at $37^{\circ} \mathrm{C}$ in $50 \mu \mathrm{l}$ of prewarmed antibody solution with $\mathrm{mAb}$ at $2 \mu \mathrm{g} / \mathrm{ml}$ and cross-linking antibodies at $1 \mu \mathrm{g} / \mathrm{ml}$. The reaction was stopped with $1 \mathrm{ml}$ of cold PBS and quick centrifugation in an Eppendorf centrifuge. The pelleted cells were lysed in $30 \mu \mathrm{l}$ of Nonidet P40 (Fluka Chemie AG, Buchs, Switzerland) 
lysis buffer (1\% (v/v) of detergent in $20 \mathrm{mM}$ Tris- $\mathrm{HCl}(\mathrm{pH} 8.1), 150 \mathrm{mM}$ $\mathrm{NaCl}$, with protease and phosphatase inhibitors Aprotinin, Leupeptin, PMSF, Sodium orthovanadate, Sodium pyrophosphate, and Sodium fluoride). Lysates remained on ice for 15-30 minutes before centrifugation at $4{ }^{\circ} \mathrm{C}$ and $14000 \mathrm{rpm}$ for $7 \mathrm{~min}$. Proteins in the supernatants were boiled in sample buffer with $\beta$-Mercaptoethanol, separated on $10 \%$ SDS polyacrylamide gels, and transferred to Nitrocellulose membranes (Hybond C-Extra, Amersham, Braunschweig, Germany). Blots were blocked with 5\% BSA (Sigma) and tyrosine phosphorylated proteins were detected with the anti-PTyr mAb 4G10 (Upstate Biotechnology Inc., Lake Placid, NY), Horseradish peroxidase-conjugated sheep anti-mouse antibodies (Amersham) and chemiluminescense detection reagents (ECL, Amersham; Renaissance, Dupont-NEN, Bad Homburg, Germany).

\section{Treatment of $\mathbf{T}$ cell clones with kinase inhibitors}

To inhibit src-related tyrosine kinases and T cell activation, Herbimycin A (Calbiochem-Novabiochem, San Diego, CA) was used at a concentration of $1.5 \mu \mathrm{M}(0.86 \mu \mathrm{g} / \mathrm{ml})$. The working concentration for each inhibitor was chosen not to be toxic by itself as determined in titration experiments. We also tested a variety of other less specific kinase-inhibitors such as Genistein $(75 \mu \mathrm{M}(20 \mu \mathrm{g} / \mathrm{ml})$, CalbiochemNovabiochem, Akiyama et al, 1987), Staurosporine $(6.7 \mu \mathrm{M}(3.125 \mathrm{ng} /$ $\mathrm{ml})$, Sigma, Tamaoki et al, 1986), or Tyrphostin (25 $\mu \mathrm{M}(5 \mu \mathrm{g} / \mathrm{ml})$, Calbiochem-Novabiochem, Gazit et al, 1989) and the PI 3-Kinaseinhibitor Wortmannin (100 nM $(42.7 \mathrm{ng} / \mathrm{ml})$, Calbiochem-Novabiochem, Powis et al, 1994). The clone cells were pre-incubated for 1$3 \mathrm{~h}$ in inhibitor-containing medium and washed before short-term stimulation assays. For overnight incubation in the presence or absence of anti-TCR/CD3 or anti-CD95 mAb, the inhibitors remained present in the culture wells.

\section{PCR-analysis of Fas Ligand expression}

FasL mRNA was analyzed using a PCR approach based on total RNA. $5 \times 10^{6}$ clone cells were incubated in the presence or absence of antiTCR or anti-CD3 mAb $(2 \mu \mathrm{g} / \mathrm{ml})$. The cells were pelleted and washed in PBS. Total RNA was isolated using the Quick Prep ${ }^{\circledR}$ Total RNA Extraction Kit (Pharmacia Biotech, Freiburg, Germany). $0.5 \mu \mathrm{g}$ RNA per sample were subjected to RT-PCR using a RNA PCR kit from Perkin Elmer (Roche Molecular Systems, Branchburg, NJ). The following oligonucleotide primers were used: for FasL: 5'-TGG-CAGAAC-TCC-GAG-AGT-CTA-3' and 5'-CAC-TGG-TAA-GAT-TGA-ACACTG-C-3', and for GAPDH 5'-GCA-GGG-GGG-AGC-CAA-AAG-GG-3' and 5'-TGC-CAG-CCC-CAG-CGT-CAA-AG-3', respectively (Eurogentec, Cologne, Germany). PCR products were analyzed following separation and transfer to nylon membranes (Hybond $\mathrm{N}^{+}$, Amersham) using the non-radioactive $\mathrm{ECL}^{\mathrm{TM}}$ direct nucleic acid labeling and detection system (Amersham). The DNA probe for GAPDH (399 bp) was generated by PCR from genomic DNA of PBMC using the GeneAmp PCR Reagent Kit with Amplitaq polymerase (Roche Molecular Systems). A Bluescript-based vector containing FasL cDNA was kindly provided by Dr. Nagata (Osaka, Japan). The FasL probe consisted of a purified Xba I fragment.

\section{Acknowledgements}

This work was supported by a fellowship from the Bundesministerium für Forschung und Technologie (AIDS-Stipendienprogramm, to O.J.). The authors thank Dr. R. Kurrle for providing mAb BMA031, and EuroCetus and Cilag $\mathrm{GmbH}$ for the gift of essential reagents. We also thank Dr. S.
Nagata for providing FasL cDNA. This work forms part of the Ph.D. thesis of H.-H. Oberg.

\section{References}

Akiyama T, Ishida J, Nakagawa S, Ogawara H, Watanabe S, Itho N, Shibuya M and Fukami $Y$ (1987) Genistein, a specific inhibitor of tyrosine-specific protein kinases. J. Biol. Chem. 262: 5592-5595

Alderson MR, Tough TW, Davis-Smith T, Braddy S, Falk B, Schooley KA, Goodwin RG, Smith CA, Ramsdell F and Lynch DH (1995) Fas ligand mediates activationinduced cell death in human T lymphocytes. J. Exp. Med. 181: 71-77

Anel A, Buferne M, Boyer C, Schmitt-Verhulst AM and Golstein P (1994) T cell receptor-induced Fas ligand expression in cytotoxic $T$ lymphocyte clones is blocked by protein tyrosine kinase inhibitors and cyclosporin A. Eur. J. Immunol. 24: $2469-2476$

Atkinson EA, Ostergaards H, Kanes K, Pinkoski MJ, Caputo A, Olszowy MW and Bleackley RC (1996) A physical interaction between the cell death protein Fas and the tyrosine kinase p59 fynT. J. Biol. Chem. 271:5968-5971

Boldin MP, Goncharov TM, Goltsev YV and Wallach D (1996) Involvement of MACH, a novel MORT1/FADD-interacting protease in Fas/APO-1- and TNF Receptorinduced cell death. Cell 85: 803-81

Brunner T, Mogil RJ, LaFace D, Yoo NJ, Mahboubi A, Echeverri F, Martin SJ, Force WR, Lynch DH, Ware CF and Green DR (1995) Cell-autonomous Fas (CD95)/ Fas-ligand interaction mediates activation-induced apoptosis in T-cell hybridomas. Nature 373: $441-444$

Cifone MG, De Maria R, Roncaioli P, Rippo MR, Azuma M, Lanier LL, Santoni A and Testi R (1994) Apoptotic signaling through CD95 (Fas/Apo-1) activates an acidic sphingomyelinase. J. Exp. Med. 180: 1547-1552

Chinnaiyan AM, O'Rourke K, Tewari M and Dixit VM (1995) FADD, a novel death domain-containing protein, interacts with the death domain of Fas and initiates apoptosis. Cell 81: 505-512

Dhein J, Daniel PT, Traut BC, Oehm A, Möller P and Krammer PH (1992) Induction of apoptosis by monoclonal anti-APO-1 class switch variants is dependent on crosslinking of APO-1 cell surface antigens. J. Immunol. 149: 3166-3173

Dhein J, Walczak H, Baeumler C, Debatin KM and Krammer PH (1995) Autocrine Tcell suicide mediated by APO-1/(Fas/CD95). Nature 373: 438-441

Dobrowsky RT, Kamibayashi C, Mumby MC and Hannun YA (1993) Ceramide activates heterotrimeric protein phosphatase 2A. J. Biol. Chem. 268: 1552315530

Dressler KA, Mathias S and Kolesnik RN (1992) Tumor necrosis factor alpha activates the shingomyelin signal transduction pathway in a cell free system. Science 255: 1715-1718

Eischen CM, Dick CJ and Leibson PJ (1994) Tyrosine kinase activation provides an early and requisite signal for Fas-induced apoptosis. J. Immunol. 153: 19471954

Gazit A, Yaish P, Gilon C and Levitzki A (1989) Tyrphostins I: synthesis and biological activity of protein tyrosine kinase inhibitors. J. Med. Chem. 32: 2344-2352

Gill BM, Nishikata H, Chan G, Delovitch TL and Ochi A (1994) Fas antigen and sphingomyelin-ceramide turnover-mediated signaling: role in life and death of $T$ lymphocytes. Immunol. Rev. 142: 113-125

Golstein P, Mattei MG, Foa C and Luciani MF (1994) Molecular mechanisms of T lymphocyte cytotoxicity. In Apoptosis and the immune response. Gregory CD, ed (New York; John Wiley and Sons) pp 143-168

Gulbins E, Bissonnette R, Mahboubi A, Martin S, Nishioka W, Brunner T, Baier G, Baier-Bitterlich G, Byrd C, Lang F, KolesnikR, Altman A and Green D (1995) FASinduced apoptosis is mediated via a ceramide-initiated RAS signaling pathway. Immunity 2: 341-351

Hane M, Lowin B, Peitsch M, Becker K and Tschopp J (1995) Interaction of peptides derived from the Fas ligand with the Fyn SH3 domain. FEBS Letters 373: 265268

Itoh N, Yonehara S, Ishii A, Yonehara M, Mizushima S-I, Sameshima M, Hase A, Seto $Y$ and Nagata $S$ (1991) The polypeptide encoded by the cDNA for human cell surface antigen Fas can mediate apoptosis. Cell 66: 233-243

Janssen O, Wesselborg S, Heckl-Östreicher B, Pechold K, Bender A, Schondelmaier S, Moldenhauer G and Kabelitz D (1991) T cell receptor/ CD3-signaling induces death by apoptosis in human T cell receptor $\gamma \delta^{+} \mathrm{T}$ cells. J. Immunol. 146: 35-39 
Janssen O, Lengl-Janßen B, Oberg H-H, Robertson MJ and Kabelitz D (1996) Induction of cell death via Fas (CD95, APO-1) may be associated with but is not dependent on Fas-induced tyrosine phosphorylation. Immunol. Lett. 49: 63-69

Jarvis WD, Kolesnick RN, Fornari FA, Traylor RS, Gewitz DA and Grant S (1994) Induction of apoptotic DNA damage and cell death by activation of the sphingomyelin pathway. Proc. Natl. Acad. Sci. USA 91: 73-77

Ju ST, Cui H, Panka DJ, Ettinger R and Marshak-Rothstein A (1994) Participation of target Fas protein in apoptosis pathway induced by $\mathrm{CD}^{+}$Th1 and $\mathrm{CD}^{+}$ cytotoxic T cells. Proc. Natl. Acad. Sci. USA 91: 4185-4189

Ju ST, Panka DJ, Cui H, Ettinger R, el-Khatib M, Sherr DH, Stanger BZ and MarshakRothstein A (1995) Fas(CD95)/FasL interactions required for programmed cell death after T-cell activation. Nature 373: 444-448

June $\mathrm{CH}$, Fletcher MC, Ledbetter JA, Schieven GL, Siegel JN, Phillips AF and Samelson LA (1990) Inhibition of tyrosine phosphorylation prevents T-cell receptor-mediated signal transduction. Proc. Natl. Acad. Sci. USA 87: 77227726

Kabelitz D and Wesselborg S(1992) Life and death of a superantigen-reaktive human $\mathrm{CD}^{+} \mathrm{T}$ cell clone: staphylococcal enterotoxins induce death by apoptosis but simultaneously trigger a proliferative response in the presence of HLA-DR ${ }^{+}$ antigen-presenting cells. Int. Immunol. 4: 1381-1389

Kabelitz D, Pohl T and Pechhold K (1993) Activation-induced cell death (apoptosis) of mature peripheral T lymphocytes. Immunol. Today 14: 338-339

Kim M-Y, Linardic C, Obeid L and Hannun Y (1991) Identification of sphingomylein turnover as an effector mechanism for the action of tumor necrosis factor alpha and gamma-interfereon: specific role in cell differentiation. J. Biol. Chem. 266: $484-489$

Kischkel FC, Hellbardt S, Behrmann I, Germer M, Pawlita M, Krammer PH and Peter ME (1995) Cytotoxicity-dependent APO-1 (Fas/CD95)-associated proteins from a death-inducing signaling complex (DISC) with the receptor. EMBO J. 14: $5579-5588$

Klas C, Debatin KM, Jonker RR and KrammerPH(1993) Activation interferes with the APO-1 pathway in mature human T cells. Int. Immunol. 5: 625-630

Krishan A (1975) Rapid flow cytometric analysis of mammalian cell cycle by Propidium iodide staining. J. Cell. Biol. 66: 188-193

Latinis KM and Koretzky GA (1996) Fas ligation induces apoptosis and Jun Kinase activation independently of CD45 and Lck in human T cells. Blood 87: 871 -875

McGahon AJ, Nishioka WK, Martin SJ, Mahboubi A, Cotter TG and Green DR (1995) Regulation of the Fas apoptotic cell death pathway by Abl. J. Biol. Chem. 270: $22625-22631$

Migita K, Eguchi K, Yojiro K, Mizokami A, Tsukada T and Nagataki S (1994) Prevention of anti-CD3 monoclonal antibody-induced thymic apoptosis by protein tyrosine kinase inhibitors. J. Immunol. 153: 3457-3465

Mollerau B, Deckert M, Deas O, Rieux-Laucat F, Hirsch F, Bernard A, Fischer A, Lynch DH, Charpentier B, Le Deist F and Senik A (1996) CD2-induced apoptosis in activated human peripheral T cells. J. Immunol. 156: 3184-3190

Muzio M, Chinnaiyan AM, Kischkel FC, O'Rourke K, Shevchenko A, Scaffidi C, Bretz JD, Zhang M, Gentz R, Mann M, Krammer PH, Peter ME and Dixit VM (1996) FLICE, a novel FADD homologous ICE/CDE-3-like protease is recruited to the CD95 (Fas/Apo-1) Death-inducing Signaling Complex. Cell 85: 817-827

Nagata S and Golstein P (1995) The Fas death factor. Science 267: 1449-1456

Orchansky PL and Teh H-S (1994) Activation-induced cell death in proliferating T cells is associated with altered tyrosine phosphorylation of TCR/CD3 subunits. J. Immunol. 153: 615-622

Oyaizu N, Than S, McCloskey TW and Pahwa S (1995) Requirement of p56 ${ }^{\text {lck }}$ in Tcell receptor/CD3-mediated apoptosis and Fas-ligand induction in Jurkat cells. Biochem. Biophys. Res. Commun. 213: 994-1001

Pechhold K, Pohl T and Kabelitz D (1994) Rapid quantification of lymphocyte subsets in heterogeneous cell populations by flw cytometry. Cytometry 16 : $152-159$

Powis G, Bonjouklian MM, Berggren A, Gallegos R, Abraham C, Ashendel L, Zalkow W, Matter WF, Dodge J, Gridey G and Vlahos CJ (1994) Wortmannin, a potent and selective inhibitor of phosphatidylinositol-3-kinase. Cancer Res. 54:24192423
Raines MA, Kolesnik RN and Golde DW (1993) Sphingomyelinase and ceramide activate mitogen-activated protein kinase in myeloid HL-60 cells. J. Biol. Chem. 268: $14572-14575$

Rouvier E, Luciani MF and Golstein P (1993) Fas involvement in Ca2 ${ }^{+}$independent T cell-mediated cytotoxicity. J. Exp. Med. 177: 195-200

Rudd CE, Janssen O, Cai J-C, da Silva AJ, Raab M and Prasad KVS (1994) Two-step TCR tyrosine and lipid kinases. Immunol. Today 15: 225-234

Russel JH (1995) Activation-induced death of mature T cells in the regulation of immune responses. Curr. Opin. Immunol. 7: 382-388

Sato T, Irie S, Kitada S and Reed JC (1995) FAP-1: a protein tyrosine phosphatase that associates with Fas. Science 268: $411-415$

Schraven B and Peter ME (1995) APO-1(CD95)-mediated apoptosis in Jurkat cells does not involve src kinases or CD45. FEBS Letters 368: 491-494

Schütze S, Potthoff K, Machlaidt D, Berkovic D, Wiegmann K and Krönke M (1992) TNF activates NF-kappa B by phosphatidylcholine-specific phopholipase Cinduced 'acidic' sphingomyeline breakdown. Cell 71: 765-776

Schulze-Osthoff K, WalczakH, Droege W and KrammerPH (1994a)Cell nucleus and DNA fragmentation are not required for apoptosis. J. Cell. Biol. 127: 15-20

Schulze-Osthoff K, Krammer PH and Droege W (1994b) Divergent signalling via APO-1/Fas and the TNF receptor, two homologous molecules involved in physiological cell death. EMBO J. 13: 4587-4596

Stalder T, Hahn S and Erb P (1994) Fas antigen is the major target molecule for CD4 ${ }^{+}$ T cell-mediated cytotoxicity. J. Immunol. 152: 1127-1133

Stanger BZ, Leder P, Lee TH, Kim E and Seed B (1995) RIP: a novel protein containing a death domain that interacts with Fas/APO-1 (CD95) in yeast and causes cell death. Cell 81: 513-523

Suda T and Nagata S (1994) Purification and characterization of the Fas-ligand that induces apoptosis. J. Exp. Med. 179: 873-879

Tamaoki T, Nomoto H, Takahashi I, Kato Y, Morimoto M and Tomita F (1986) Staurosporine, a potent inhibitor of phospholipid/Ca ${ }^{++}$-dependent protein kinase. Biochem. Biophys. Res. Commun. 135: 397-402

Taupin JL, Tian Q, Kedersha N, Robertson M and Anderson P (1995) The RNAbinding protein TIAR is translocated from the nucleus to the cytoplasm during Fas-mediated apoptotic cell death. Proc. Natl. Acad. Sci. USA 92: $1629-1633$

Tian Q, Streuli M, Saito H, Schlossman SF and Anderson P (1991) A polyadenylate binding protein localized to the granules of cytolytic lymphocytes induces DNA fragmentation. Cell 67: 629-639

Tian Q, Taupin JL, Elledge S, Robertson M and Anderson P (1995) Fas-activated serine/threonine kinase (FAST) phosphorylates TIA-1 during Fas-mediated apoptosis. J. Exp. Med. 182: 865-874

Uehara Y, Fukazawa H, Murakami Y and Mizuno S (1989) Irreversible inhibition of vsrc tyrosine kinase activity by Herbimycin A and its abrogation by sulfhydryl compounds. Biochem. Biohys. Res. Commun. 163: 803-809

Vignaux F, Vivier E, Malissen B, Depraetere V, Nagata S and Golstein P (1995) TCR/ CD3 coupling to Fas-based cytotoxicity. J. Exp. Med. 181: 781-786

Wange RL and Samelson LE (1996) Complex complexes: signaling at the TCR. Immunol. Today 5: 197-205

Wesselborg S, Janssen O, Pechhold K and Kabelitz D (1991) Selective activation of $\gamma / \delta^{+} \mathrm{T}$ cell clones by single anti-CD2 antibodies. J. Exp. Med. 173: $297-304$

Wesselborg S, Janssen O and Kabelitz D (1993a) Induction of activation-driven death (apoptosis) in activated but not resting peripheral blood T cells. J. Immunol. 150: $4338-4345$

Wesselborg S, Prüfer U, Wild M, Schraven B, Meuer SC and Kabelitz D (1993b) Triggering via the alternative CD2 pathway induces apoptosis in activated human T lymphocytes. Eur. J. Immunol. 23: 2707-2710

Yonehara S, Ishii A and Yonehara M (1989) A cell-killing monoclonal antibody (antiFas) to a cell surface antigen co-downregulated with the receptor for tumor necrosis factor. J. Exp. Med. 169: 1747-1756 